\title{
CS Research Square \\ In-hospital Mortality in SARS-CoV-2 stratified by Gender: A Retrospective Study
}

\author{
Mohammed Al Jarallah
}

Department of Cardiology, Sbah Al Ahmad Cardiac Center, Kuwait

\section{Rajesh Rajan ( $\nabla$ cardiology08@gmail.com )}

Sabah Al Ahmad Cardiac Center, Al Amiri Hospital https://orcid.org/0000-0002-0249-0440

\section{Raja Dashti}

Department of Cardiology, Sabah Al Ahmad Cardiac Center, Kuwait

\section{Ahmad R Alsabar}

University of Strathclyde Department of Mathematics: University of Strathclyde Department of

Mathematics and Statistics

\section{Jiazhu Pan}

University of Strathclyde STAMS: University of Strathclyde Department of Mathematics and Statistics

\section{Zhanna D Kobalava}

RUDN Medicinskij institut: Rossijskij universitet druzby narodov Medicinskij institut

\section{Hassan Abdelnaby}

Al Sabah Hospital Kuwait \& Suez canal University

\section{Wael Aboelhassan}

Jaber Al Ahmed Al Jaber Al Sabah Hospital

\section{Farah Almutairi}

Farwaniya Hospital

\section{Naser Alotaibi}

Al Adan Hospital

\section{Mohammad Al Saleh}

Farwaniya Hospital

\section{Noor AINasrallah}

Al Adan Hospital

\section{Bader Al-Bader}

Farwaniya Hospital

\section{Haya Malhas}

Mubarak Al-Kabeer Hospital

\section{Maryam Ramadhan}

Kuwait University and Maternity Hospital

\section{Mahdy Hamza}

Al Adan Hospital 


\section{Peter A Brady}

Advocate Illinois Masonic Medical Center

Ibrahim Al-Zakwani

Sultan Qaboos University

Mohammed Abdullah

Department of Pediatrics, Infectious Diseases Hospital Kuwait

Moudhi Alroomi

Infectious Disease Hospital Kuwait

\section{Research Article}

Keywords: Gender, COVID-19, In-hospital mortality, Sex, SARS-CoV-2

Posted Date: August 2nd, 2021

DOI: https://doi.org/10.21203/rs.3.rs-727098/v1

License: (c) (1) This work is licensed under a Creative Commons Attribution 4.0 International License.

Read Full License 


\section{Abstract}

Background: The aim of this study was to determine in-hospital mortality in patients presenting with acute respiratory syndrome corona virus 2 (SARS-CoV-2) and to evaluate for any differences in outcome according to gender.

Methods: Patients with SRS-CoV-2 infection were recruited into this retrospective cohort study between February 26 and September 8, 2020 and stratified according to the gender.

Results: In total of 3360 patients (mean age $44 \pm 17$ years) were included, of whom 2221 (66\%) were male. The average length of hospitalization was 13 days (range: 2-31 days). During hospitalization and follow-up 176 patients (5.24\%) died. Mortality rates were significantly different according to gender ( $\mathrm{p}=$ $<0.001$ ). Specifically, male gender was associated with significantly greater mortality when compared to female gender with results significant at an alpha of $0.05, L L=28.67, d f=1, p=0.001$, suggesting that gender could reliably determine mortality rates. The coefficient for the males was significant, $B=1.02, S E$ $=0.21, H R=2.78, p<.001$, indicating that an observation in the male category will have a hazard 2.78 times greater than that in the female category. Multivariate logistic regression confirmed male patients admitted with SARS-CoV-2had higher cumulative all-cause in-hospital mortality (6.8\% vs. $2.3 \%$; adjusted odds ratio (aOR), 2.80; 95\% (Cl): [1.61 - 5.03]; $p<0.001)$.

Conclusions: Male gender was an independent predictor of in-hospital death in this study. The mortality rate among male SARS-CoV-2 patients was 2.8 times higher when compared with females.

\section{Highlights}

- In-hospital mortality in SARS-CoV-2 male patients are 2.8 times higher when compared to females.

- Average length of ICU stay was longer in males SARS-CoV-2 patients

\section{Background}

In-hospital mortality in patients affected with SARS-CoV-2 reportedly ranges from $17-77 \%$. [1, 2, 3] Recent data from 38 countries suggests that mortality may be up to 1.7 times higher males than in females. [4] The prevalence of SARS-CoV-2 infection was also reportedly higher in males compared with females. [5, 6] Previous studies in patients admitted with MERS and SARS-CoV have also reported a higher mortality amongst males [7, 8], who appear to be more susceptible to infection than females. [9] One contributory factor may be smoking history which is more prevalent amongst males. [10] The lower incidence of SARS-CoV-2 in females may also be related to oestrogen-related protection and X-linked gene-related immune responses. [11,12]

\section{Methods}


All patients aged 18 and older diagnosed with SRS-CoV- between February 26 and September 8, 20202 were included both Kuwaitis and non-Kuwaitis. All data were abstracted from electronic medical records of two tertiary care hospitals in Kuwait: Jaberl-hmed Hospital and AlAdan General Hospital. A positive RTR swab from the nasopharynx confirmed SRS-oV-2 infection. [13] All patients were treated with a standard universal protocol according to The Ministry of Health, Kuwait. The standing committee for health coordination and medical research at the Ministry of Health in Kuwait approved the study protocol and accepted the request for waiver of the consent (Institutional the requirement of informed \1081422).

The primary endpoint was mortality due to COVID-19, as specified by ID 10 code U07.1. The collected data comprised socioeconomic facotrs, co-morbidities, clinical presentation, test results, and ICU and hospital admission duration. For data entry, an electronic case-record form (CRF) was employed.

\section{Statistical Analysis}

Descriptive statistics were used to summarise clinical data. Categorical variables were presented as frequencies and percentages, and the Pearson's X2 test used to analyse them. Continuous variables were summarized as mean and standard deviation.

A multivariable logistic regression was used to determine the impact of gender on all-cause mortality. Input vairables included gender, age, neutrophils, platelet count, and heamoglobin were used to adjust the odds ratios (oRs) for in-hospital all-cause mortality outcome. A Cox proportional hazards model was utilised to see if gender had a major impact on the risk of mortality. The significance threshold was set at p<0.05. R statistical packages [14] and SPSS version 27 (SPSS, Chicago, IL, US) were used to perform statistical analyses.

\section{Results}

A total of 3360 study participants were included. The mean age was $44 \pm 17$ years, and $2221(66 \%)$ of the patients were males. The median length of hospital stay was 13 (range 2-31) days. In this cohort 176 patients $(5.24 \%)$ died with significantly higher mortality in males $(p=<0.001)$. [Table 1 ].

When compared to females, males had significantly higher hemoglobin (132 vs $177 \mathrm{~g} / \mathrm{L} ; p<0.001)$, white blood cell (8.1 vs $\left.7.310^{9} / \mathrm{L} ; p<0.001\right)$ and neutrophil ( 57 vs $\left.54 / \mathrm{mcL} ; p<0.001\right)$ counts, prothrombin (15.6 vs $14.6 \mathrm{sec} ; p=0.016)$ and activated partial thrombopasltin ( $37.8 \mathrm{vs} 35.4 \mathrm{sec} ; p=0.047)$ times, as well as international normalized ratio(1.2 vs $\left.1.110^{9} / \mathrm{L} ; p=0.016\right)$ ( Table 2),.

Mortality was higher in individuals with lower haemoglobin $(124,22.4 \%)$ when compared to individuals with higher haemoglobin $(52,0.82 \% ; p$ 0.001). Individuals with a haemoglobin level less than $100 \mathrm{~g} / \mathrm{L}$ had a greater cumulative all-cause in-hospital mortality than those with haemoglobin levels higher than 100 g/L (22.4\% vs. $0.8 \%$; R, 0.29; $95 \%$ Cl: [0.18-0.46]; p 0.001). In-hospital mortality was associated with a higher neutrophil count $[\mathrm{aOR}, 1.17 ; 95 \% \mathrm{Cl}:(1.14-1.20, \mathrm{p} 0.001)$ and a lower platelet count $[\mathrm{aOR}, 1.00$; 
$95 \%$ l:(1.00-1.00, $p=0.005)$. With respect to all-cause cumulative in-hospital mortality, age had no significant impact among the groups (aOR, 1.00; 95\% Cl [0.98-1.02]; p 0.960). [Table 3] Male gender had a large impact on cumulative all-cause in-hospital mortality (6.8\% vs. $2.3 \%)[R, 2.80 ; 95 \%$ Cl: $[1.61,5.03] ; p$ 0.001). [Table 3].

Kaplan-Meier survival probability plots were used for the analysis based on gender. Each plot depicts the survival probabilities of various groups over time. Male sex was related to increased mortality (KaplanMeier survival probability plot). The model's results were significant and could not be explained by an alpha of $0.05, L L=28.67, d f=1, p=0.001$, showing that gender could appropriately estimate the risk of mortality. The coefficient for male gender was significant, $B=1.02, \mathrm{SE}=0.21, \mathrm{HR}=2.78, \mathrm{p} .001 \mathrm{p}<.001$, indicating that male gender was associated with risk of mortality 2.78 times greater than female gender at any given point in time. Gender was observed to be important in predicting in-hospital mortality among SRS-oV-2 patients in this study. [FIGURE 1]

\section{Discussion}

The main finding of our study is that male gender is an independent predictor of in-hospital mortality in patients diagnosed with SARS-CoV-2.. Specifically, mortality in males with SARS-CoV-2 was 2.8 times higher than in females. Moreover, average length of ICU stay was longer in males. However, females were on average older than male patients. Although older in age, especially middle age and above, had higher mortality, this did not reach statistical significance. A higher neutrophil count and a lower platelet count had a significant impact on in-hospital mortality. The mortality rate was also seen higher in those with lower hemoglobin levels, which has been reported previously. [15] Reasons for these findings most probably relate to severity of infection and the extent of immune response that could be associated with increase in mortality.

One reason for higher mortality observed in males could be the higher prevalence of ACE-2 in the lungs. [16] Oestrogen-related protection in females may suppress SARS-CoV-2, thereby leading to lower mortality. $[17,18]$ The male to female ratio observed in our study was higher than that in prior studies $(1.5: 1)$. $[19,20]$ The significance of gender is equally important as other risk factors in SARS-CoV-2 infection. [21] Several studies have reported higher mortality from SARS-CoV-2 in males. For example, in 144,279 patients in England and Wales significantly higher mortality was observed in males. [22] Similar findings were reported in Europe and Wuhan. $[23,24]$ In addition, a study from Italy reported lower mortality in hospitalized females, but similar mortality among males and females in critically ill SARSCoV-2 patients. [25] while more critically ill male patients were seen in a study conducted in Europe. [26]

Delays in admission have also contributed to an increased rate of mortality in male patients in the setting of SARS-CoV-2. [27] Younger males and elderly females were the most vulnerable in terms of mortality. [28] In a systematic review and meta-analysis, it was evident that both alcohol consumption and smoking increase mortality in males and females. [29] 
Our study does have some limitations. First, the study is retrospective limiting causal inference while unmeasured confounding factors, such as clinical co-morbidities and medications, could have affected the outcomes. Also, since our study included all positive COVID-19 patients in Kuwait it likely includes mainly milder cases of the disease.

\section{Conclusions}

This study demonstrated that gender is an independent predictor of in-hospital mortality in SARS-CoV-2 patients with males 2.8 times more likely to die than females. Despite males having a shorter overall hospitalization than femaies males spent a greater proportaion of time in intensive care unit than females. More prospective studies are required to better understand sex-related morbidity and mortality.

\section{Abbrevations}

SARS-CoV-2 = severe acute respiratory syndrome coronavirus 2

ICU = Intensive Care Unit

RT-PCR $=$ Reverse Transcription Polymerase Chain Reaction

$\mathrm{Cl}=$ Confidence Interval

$\mathrm{aOR}=$ adjusted Odds Ratio

$\mathrm{CRF}=$ Case Record Form

\section{Declarations}

Ethics approval statement: This study was approved by the ethics committee and Ministry of Health Kuwait

Patient consent statement: Patient consented was not mandated for this retrospective observational study. Permission to reproduce material from other sources: No material from other sources is included in this study.

Data availability statement: The data that support the findings of this study are available on request from the corresponding author. The data are not publicly available due to privacy or ethical restrictions.

Competing interests: The authors declare that they have no competing interests.

Funding statement: No funding available for this study

Author's contributions : 
MAJ participated in analysis and manuscript preparation. RR participated in data analysis and manuscript preparation. AAS and JP did the statistical analysis as well as manuscript review. All authors had access to data and take responsibility for the integrity of data and the accuracy of data analysis. All authors have read and approved the manuscript.

Acknowledgements: "Not applicable"

\section{References}

1. Karagiannidis C, Mostert C, Hentschker C, Voshaar T, Malzahn J, Schillinger G, et al. Case characteristics, resource use, and outcomes of 10021 patients with COVID-19 admitted to 920 German hospitals: an observational study. Lancet Respir Med. 2020;8:853-62.

2. Ñamendys-Silva SA, Gutiérrez-Villaseñor A, Romero-González JP. Hospital mortality in mechanically ventilated COVID-19 patients in Mexico. Intensive Care Med. 2020;46:2086-8.

3. Hallal PC, Hartwig FP, Horta BL, Silveira MF, Struchiner CJ, Vidaletti LP, et al. SARS-CoV-2 antibody prevalence in Brazil: results from two successive nationwide serological household surveys. Lancet Glob Health. 2020;8:e1390-8.

4. Scully EP, Haverfield J, Ursin RL, Tannenbaum C, Klein SL. Considering how biological sex impacts immune responses and COVID-19 outcomes. Nat Rev Immunol. 2020;20:442-7.

5. Sha J, Qie G, Yao Q, Sun W, Wang C, Zhang Z, et al. Sex Differences on Clinical Characteristics, Severity, and Mortality in Adult Patients With COVID-19: A Multicentre Retrospective Study; Front Med. 2021;8:607059.

6. Haitao T, Vermunt JV, Abeykoon J, Ghamrawi R, Gunaratne M, Jayachandran M, et al. COVID-19 and sex differences: mechanisms and biomarkers. Mayo Clin Proc. 2020;95:2189-203.

7. Alghamdi I, Hussain I, Alghamdi M, Almalki S, Alghamdi M, Elsheemy M. The pattern of Middle East respiratory syndrome coronavirus in Saudi Arabia: a descriptive epidemiological analysis of data from the Saudi Ministry of Health. Int J Gen Med. 2014;7:417-23.

8. Karlberg J, Chong DS, Lai WY. Do men have a higher case fatality rate of severe acute respiratory syndrome than women do? Am J Epidemiol. 2004;159:229-31.

9. Klein SL, Flanagan KL. Sex differences in immune responses. Nat Rev Immunol. 2016;16:626-38.

10. Cai H. Sex difference and smoking predisposition in patients with COVID-19. Lancet Respir Med. 2020;8:e20.

11. Channappanavar R, Fett C, Mack M, Ten Eyck PP, Meyerholz DK, Perlman S. Sex-based differences in susceptibility to severe acute respiratory syndrome coronavirus infection. J Immunol. 2017; 198:4046-53.

12. Robinson DP, Huber SA, Moussawi M, Roberts B, Teuscher C, Watkins R, et al. Sex chromosome complement contributes to sex differences in coxsackievirus B3 but not influenza A virus pathogenesis. Biol Sex Differ. 2011;2:8. 
13. Al-Jarallah M, Rajan R, Dashti R, Al Saber A, Pan J, Zhanna KD, Abdelnaby H, Aboelhassan W, Almutairi F, Abdullah M, Alotaibi N, Al Saleh M, Al Nasrallah N, Al-Bader B, Malhas H, Ramadhan M, Hamza M, Brady PA, Al-Zakwani I, Alroomi M. In-hospital mortality in SARS-CoV-2 stratified by serum 25-hydroxy-vitamin D levels: A retrospective study. J Med Virol. 2021 Jun 7. doi: 10.1002/jmv.27133. Epub ahead of print. PMID: 34101207.

14. Laine T, Reyes EM. Tutorial: survival estimation for Cox regression models with time-varying coefficients using SAS and R. J Stat Softw 2014;61:1-23.

15. Al-Jarallah M, Rajan R, Saber AAl, Pan J, Al-Sultan AT, Abdelnaby H, et al. In-hospital mortality in SARS-CoV-2 stratified by hemoglobin levels: A retrospective study. eJHaem. 2021;1-5.

16. Zhao Y, Zhao Z, Wang Y, Zhou Y, Ma Y, Zuo W. Single-cell RNA expression profiling of ACE2, the putative receptor of Wuhan 2019-nCov. bioRxiv. 2020; doi:10.1101/2020.01.26.919985.

17. Jin J, Bai P, He W, Wu F, Liu X, Han D, et al. Gender differences in patients with COVID-19: focus on severity and mortality. Front Public Health. 2020;8:152.

18. Channappanavar R, Fett C, Mack M, Ten Eyck PP, Meyerholz DK, Perlman S. Sex-based differences in susceptibility to severe acute respiratory syndrome coronavirus infection. $J$ Immunol. 2017;198:4046-53.

19. Richardson S, Hirsch JS, Narasimhan M, Crawford JM, McGinn T, Davidson KW, et al. Presenting characteristics, comorbidities, and outcomes among 5700 patients hospitalized with COVID-19 in the New York City area. JAMA. 2020;323:2052-9.

20. Mehra MR, Desai SS, Kuy S, Henry TD, Patel AN. Cardiovascular disease, drug therapy, and mortality in Covid-19. N Engl J Med. 2020;382:2582.

21. Spagnolo PA, Manson JE, Joffe H. Sex and gender differences in health: what the COVID-19 pandemic can teach us. Ann Intern Med. 2020;173:385-6.

22. Mohamed MO, Gale CP, Kontopantelis E, Doran T, de Belder M, Asaria M, et al. Sex Differences in Mortality Rates and Underlying Conditions for COVID-19 Deaths in England and Wales. Mayo Clin Proc. 2020;95:2110-24.

23. Ahrenfeldt LJ, Otavova M, Christensen K, Lindahl-Jacobsen R. Sex and age differences in COVID-19 mortality in Europe. Wien Klin Wochenschr. 2021;133:393-8.

24. Chen J, Bai H, Liu J, Chen G, Liao Q, Yang J, et al. Distinct Clinical Characteristics and Risk Factors for Mortality in Female Inpatients With Coronavirus Disease 2019 (COVID-19): A Sex-stratified, Largescale Cohort Study in Wuhan, China. Clin Infect Dis. 2020;71:3188-95.

25. Raimondi F, Novelli L, Ghirardi A, et al. Covid-19 and gender: lower rate but same mortality of severe disease in women-an observational study. BMC Pulm Med. 2021;21:96.

26. Gebhard C, Regitz-Zagrosek V, Neuhauser HK, Morgan R, Klein SL. Impact of sex and gender on COVID-19 outcomes in Europe. Biol Sex Differ. 2020;11:29.

27. Ma C, Gu J, Hou P, Zhang L, Bai Y, Guo Z, et al. Incidence, clinical characteristics and prognostic factor of patients with COVID-19: a systematic review and meta-analysis. medRxiv, 2020; doi:10.1101/2020.03.17.20037572. 
28. National Center for Health Statistics. Centers for Disease Control and Prevention; Bethesda, MD: 2020. Provisional COVID-19 Death Counts by Sex, Age, and State 2020.

(https://data.cdc.gov/NCHS/Provisional-COVID-19-Deaths-by-Sex-and-Age/9bhg-hcku)

29. Abate BB, Kassie AM, Kassaw MW, Aragie TG, Masresha SA. Sex difference in coronavirus disease (COVID-19): a systematic review and meta-analysis. BMJ Open. 2020;10:e040129.

\section{Tables}

Table 1: Demographics and clinical characteristics of the cohort stratified by gender among patients admitted with SARS-CoV 2.

\begin{tabular}{|c|c|c|c|c|c|}
\hline Characteristic & $\begin{array}{l}\text { All } \\
N=3360\end{array}$ & $\begin{array}{l}\text { Female } \\
n=1139\end{array}$ & $\begin{array}{l}\text { Male } \\
n=2221\end{array}$ & $\begin{array}{l}\text { p- } \\
\text { value }\end{array}$ & $\mathbf{N}$ \\
\hline Age, Mean $\pm S D$, years & $44 \pm 17$ & $43 \pm 19$ & $44 \pm 16$ & 0.093 & 3360 \\
\hline ICU admission, median (IQR), days & $0(0-4)$ & $0(0-2)$ & $0(0-4)$ & $<0.001$ & 3360 \\
\hline $\begin{array}{l}\text { Length of hospital stay, median (IQR), } \\
\text { days }\end{array}$ & $13(2-31)$ & $14(2-29)$ & $13(2-32)$ & 0.002 & 2900 \\
\hline ICU to discharge, median (IQR), days & $9(0-39)$ & $6(0-23)$ & $10(0-39)$ & 0.008 & 416 \\
\hline Admission to ICU, median (IQR), days & $1.5 \pm 2.9$ & $\begin{array}{l}1.4 \pm \\
2.1\end{array}$ & $1.5 \pm 3.0$ & 0.684 & 257 \\
\hline Mortality, n (\%) & $\begin{array}{l}176 \\
(5.2 \%)\end{array}$ & $26(2.3 \%)$ & $\begin{array}{l}150 \\
(6.8 \%)\end{array}$ & $<0.001$ & 3360 \\
\hline
\end{tabular}

SD, standard deviation; ICU, intensive care unit; IQR, interquartile range.

Percentages might not add up to $100 \%$ due to rounding off.

Table 2: Laboratory investigations stratified by gender. 


\begin{tabular}{|lccccc|}
\hline Characteristic, & All & Female & Male & p-value & $\mathbf{N}$ \\
mean $\pm S D$ & $\mathbf{N}=3360$ & $\mathbf{n = 1 1 3 9}$ & $\mathbf{n = 2 2 2 1}$ & & \\
\hline Hemoglobin, g/L & $127(21.7)$ & $117(15.1)$ & $132(22.8)$ & $<0.001$ & 3360 \\
\hline WBC count, 109/L & $7.85(4.74)$ & $7.34(3.76)$ & $8.12(5.15)$ & $<0.001$ & 3345 \\
\hline Neutrophils, /mcL & $56.0(15.1)$ & $54.2(14.4)$ & $56.9(15.4)$ & $<0.001$ & 3344 \\
\hline Platelets, 109/L & $305(120)$ & $306(110)$ & $304(125)$ & 0.699 & 3345 \\
\hline Prothrombin time, sec & $15.3(5.98)$ & $14.6(4.56)$ & $15.6(6.49)$ & 0.016 & 851 \\
\hline INR & $1.14(0.49)$ & $1.09(0.37)$ & $1.17(0.54)$ & 0.016 & 851 \\
\hline aPTT, sec & $37.1(16.6)$ & $35.4(14.0)$ & $37.8(17.6)$ & 0.047 & 799 \\
\hline
\end{tabular}

SD, standard deviation; WBC, white blood cell count; INR, international normalized ratio; APTT, activated partial thromboplastin time.

Table 3: Predictors of in-hospital mortality by univariate and multivariate logistic regression.

\begin{tabular}{|c|c|c|c|c|c|}
\hline \multicolumn{2}{|l|}{$\begin{array}{l}\text { In-hospital } \\
\text { mortality }\end{array}$} & Alive & Dead & $\begin{array}{l}\text { Univariate } \\
\text { OR ( } 95 \% \mathrm{Cl}, \mathrm{p}- \\
\text { value) }\end{array}$ & \multirow{2}{*}{$\begin{array}{l}\text { Multivariate logistic } \\
\text { regression } \\
\text { aOR ( } 95 \% \mathrm{Cl} \text {, p-value) }\end{array}$} \\
\hline & & & & & \\
\hline \multirow[t]{2}{*}{ Gender, n (\%) } & Female & $\begin{array}{l}1113 \\
(97.7)\end{array}$ & $\begin{array}{l}26 \\
(2.3)\end{array}$ & - & - \\
\hline & Male & $\begin{array}{l}2071 \\
(93.2)\end{array}$ & $\begin{array}{l}150 \\
(6.8)\end{array}$ & $\begin{array}{l}3.10(2.07-4.83 \\
p<0.001)\end{array}$ & $\begin{array}{l}2.80(1.61-5.03 \\
p<0.001)\end{array}$ \\
\hline Age, years & Mean $\pm S D$ & $43 \pm 17$ & $57 \pm 12$ & $\begin{array}{l}1.05(1.04-1.06 \\
p<0.001)\end{array}$ & $\begin{array}{l}1.00(0.98-1.02 \\
p=0.960)\end{array}$ \\
\hline Netrophils, \% & Mean $\pm S D$ & $\begin{array}{l}55 \pm \\
13.6\end{array}$ & $87 \pm 8$ & $\begin{array}{l}1.23(1.20-1.26 \\
p<0.001)\end{array}$ & $\begin{array}{l}1.17(1.14-1.20 \\
p<0.001)\end{array}$ \\
\hline Platelets, $10^{9} / \mathrm{L}$ & Mean $\pm S D$ & $\begin{array}{l}288 \pm \\
103\end{array}$ & $\begin{array}{l}217 \pm \\
151\end{array}$ & $\begin{array}{l}0.99(0.99-0.99 \\
p<0.001)\end{array}$ & $\begin{array}{l}1.00(1.00-1.00 \\
p=0.005)\end{array}$ \\
\hline \multirow[t]{2}{*}{$\begin{array}{l}\text { Hemoglobin, } \\
\text { g/L }\end{array}$} & $\begin{array}{l}\mathrm{HB}<= \\
100\end{array}$ & $\begin{array}{l}430 \\
(77.6)\end{array}$ & $\begin{array}{l}124 \\
(22.4)\end{array}$ & - & - \\
\hline & $\mathrm{HB}>100$ & $\begin{array}{l}6325 \\
(99.2)\end{array}$ & $\begin{array}{l}52 \\
(0.8)\end{array}$ & $\begin{array}{l}0.03(0.02-0.04 \\
p<0.001)\end{array}$ & $\begin{array}{l}0.29(0.18-0.46 \\
p<0.001)\end{array}$ \\
\hline
\end{tabular}

Number in data frame $=6931$, Number in model $=3344$, Missing $=3587$, AIC $=554.1, C$-statistic $=0.976$, $\mathrm{H} \& \mathrm{~L}=\mathrm{Chi}-\mathrm{sq}(8) 2.97(p=0.936)$. 
$\mathrm{OR}$, odds ratio; aOR, adjusted odds ratio; $\mathrm{Cl}$, confidence interval; .

Multivariable analyses were conducted using logistic regression models utilizing the simultaneous method. The models were adjusted for gender, age, neutrophils, hemoglobin, and platelet.

\section{Figures}

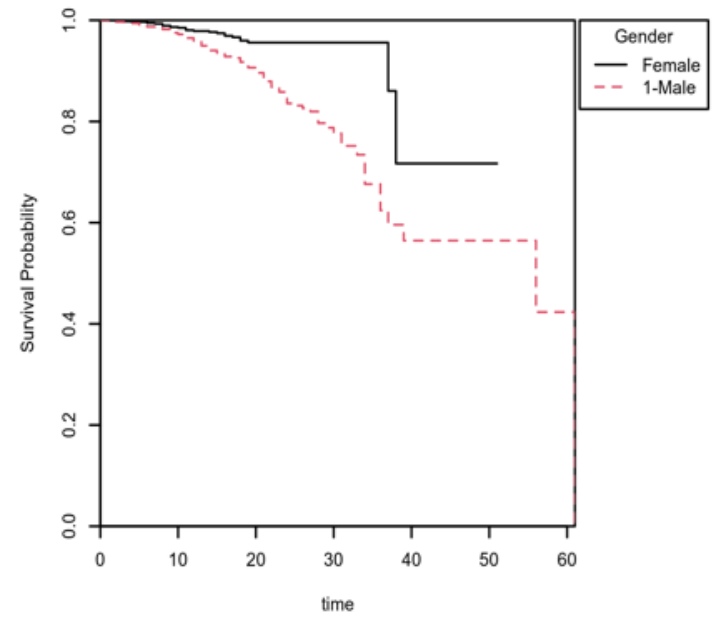

Number at Risk

$\begin{array}{lllll}\text { M } & 1968 & 1113 & 228 & 26\end{array}$

F $\quad 932 \quad 668 \quad 212 \quad 23$

Cox Proportional Hazards Regression Coefficients for Gender

\begin{tabular}{crrrrrr}
\hline Variable & $B$ & $S E$ & $95 \%$ CI & $z$ & $p$ & $H R$ \\
\hline Male & 1.02 & 0.21 & $\lceil 0.60,1.44]$ & 4.79 & $<.001$ & 2.78 \\
\hline
\end{tabular}

\section{Figure 1}

Kaplan-Meier survival plot of Mortality grouped by Gender 